\title{
The Mediating effect of Organizational Citizenship Behavior on the Organizational Justice and Organizational Performance in Small and Medium-Sized Enterprise of China
}

\author{
Mohamad Hisyam Selamat ${ }^{1} \&$ Guo Wan Ran ${ }^{1}$ \\ ${ }^{1}$ Faculty of Business, Accounting\&Management, SEGi University, Petaling Jaya, Malaysia \\ Correspondence: Mohamad Hisyam Selamat, Faculty of Business, Accounting \& Management, SEGi University, \\ 47810 Petaling Jaya, Selangor, Malaysia. E-mail: mohdhisyam@segi.edu.my
}

Received: July 29, 2019

Accepted: August 20, 2019

Online Published: August 25, 2019

doi:10.5539/ijbm.v14n9p173

URL: https://doi.org/10.5539/ijbm.v14n9p173

\begin{abstract}
This study examined the factors that influencing small and medium-sized enterprise (SMEs)' performances with the mediating effect of organizational citizenship behavior in China. Its purpose is to motivate and improve the small and medium-sized enterprise' performance. The examined factors were distributive justice, procedural justice, interactional justice. This study uses cross-sectional survey to verify the theoretical framework. The survey data in this study were collected from 251 employees of SMEs in China.The study result shows that distributive justice, interactional justice had significant influence on the organizational performance; distributive justice, procedural justice, interactional justice had significant influence on the organizational citizenship behavior; Meanwhile, procedural justice can influence organizational performance through the meditating role of organizational citizenship behavior. The results of this study could provide a development strategy for SMEs in China through the relationship organizational justice and organizational performance.
\end{abstract}

Keywords: organizational justice, organizational citizenship behavior, organizational performance

\section{Introduction}

In the world economic system, SMEs promote the economic development of all countries in the world and maintain the social stability of all regions (Abdin, 2017). At present, SMEs exist in large numbers and universally in developed and developing countries. Since China's reform and opening up, SMEs have developed rapidly. According to the 2018 survey report of the National Federation of Industry and Commerce on SMEs, by the end of 2018, SMEs had reached more than 12 million households in China. SMEs provided $80 \%$ of urban employment posts, contributed more than $75 \%$ of enterprise technological innovation, and created about $60 \%$ of the value of final products and services equivalent to gross domestic product (Tang, 2019). SMEs have become the main force of economic growth, the driving force of increasing fiscal revenue, the main way of expanding employment scale, and the force of enhancing scientific and technological innovation (Liu \& Jin, 2019).

Although SMEs in China are showing strong vitality, and their comprehensive quality is constantly improving, these problems are seriously hindered by the factors such as the level of economic development, social culture and entrepreneurship environment in China (Wang, 2016). SMEs generally have defects and shortcomings such as low technology level, lack of talents, weak competitiveness and backward management level as a single individual. The average life span of SMEs in the world is 6-10 years, while that of SMEs in China is only 3-4 years (Zhaoi, 2016). It can be seen that there is a huge gap between the development level of SMEs in China and average level of the world.

From the above discussion it is clear that improving organizational performance of SMEs of China has become a challenge to many scholars and entrepreneurs. Thus, this study intends to examine factors influencing SMEs' performance in China. Previous researches on SMEs' performance were linked to organizational issues (employee satisfaction, profit, organizational productivity, customer satisfaction, performance measurement system, human resource management practices, strategic planning) and national issues (economic growth, rules and policies) (Paul \& Anantharaman, 2003; Hillman \& Keim, 2001; Kaplan \& Norton, 1996; Ruekert, Walker, \& Roering, 1985). In this study, however, studied the performance of SMEs from the perspective of individuals or employees of SMEs'. This is because of the critical role of employees in managing and implementing daily 
activities of SMEs (Garg \& Dhar, 2017; Garg \& Dhar, 2014; Balkin et al., 2000; Utterback, 1994; Wolfe, 1994).

Previous studies have mostly proposed the impact of organizational justice on organizational performance (Wang, 2009),only a few studies showed organizational justice indirectly influence organizational performance through intermediary factors (Cheung \& Law, 2013) and some studies have not further explored the impact of three dimensions of organizational justice on organizational performance through intermediary factors. Therefore, in this study, a new conceptual framework is designed. The conceptual framework consists of organizational justice, organizational citizenship behavior, organizational performance. Organizational justice is a kind of sense of fairness and the corresponding behavior response, which are generated in a certain organizational environment (Neuhoff \& Moorman, 1993). Organizational justice includes three dimensions: distributive justice, procedural justice and interactional justice (Neuhoff \& Moorman, 1993). The study provided the framework that organizational justice could develop employees' organizational citizenship behavior and in turn improve SMEs' performance.

\section{Theoretical Overview}

In order to understand the theoretical understanding of organizational performance in this study, the propose of the organizational performance is based on concepts of the organizational justice and organizational citizenship behaviour. In the following sections, organizational justice and organizational citizenship behaviour are provided.

\subsection{Organizational Performance}

Organizational performance is a way or method to measure the achievement of organizational goals (Long, 2013). Because of the different definitions, contents, processes or types of organizational goals, scholars have different definitions of organizational performance from different perspectives and ways. According to Ruekert, Walker and Roering (1985), organizational performance consists of efficiency, effectiveness and adaptability. Efficiency refers to the ratio of resources input to output. Effectiveness refers to the sales growth rate and market share of products or services provided by the organization. Adaptability refers to the ability of an organization to respond to changes or threats in the external environment. Pritchard R D. (1995) argued that early research on organizational performance mainly uses productivity as a measure. Delaney D T. (1996) posed that organizational performance was the operating efficiency of an organization within a certain operating range.

In addition, performance measurement is defined by the interaction among members of the organization. It can be seen that the internal atmosphere of the organization will affect the achievement of organizational performance. Chen (2005) and other scholars support the classification of organizational performance indicators. They believed that there are two kinds of measurement of organizational performance: single indicator and multiple indicators. Among them, single indicators refer to the indicators of organizational achievements, such as employee satisfaction, profit, organizational stability, organizational productivity and other factors. Multiple indicators avoid the one-sidedness of single indicators to measure organizational performance, and measure organizational goals and organizational performance from multiple perspectives. Throughout the research of scholars, most of them use survey data such as questionnaires, interviews and other research data as sample data to measure the level of organizational performance of enterprises. Because the survey data are greatly influenced by human factors, researchers cannot get completely objective data. Although some scholars use financial data to explain organizational performance, with the development of market economy, pure financial data cannot fully explain the quality of organizational performance.

Therefore, some researchers began to pay attention to non-financial factors affecting organizational performance, so organizational performance is regarded as the effectiveness and efficiency in the process of achieving organizational goals. So, there is no doubt that organizational performance as one of the important indicators of organizational value exists. Therefore, this study used Steers (1975), Lin Yiping (2001), Xie Hong Ming (2005) and Chen Guo Quan (2005) to define organizational performance. So, organizational performance was defined as the indicators of organizational achievements, such as employee satisfaction, profit, organizational stability and organizational life. Then the relative value of scale was used to evaluate the organizational performance of SMEs.

\subsection{Organizational Citizenship Behaviour}

The concept of organizational citizenship behaviour (OCB) was first proposed by Barnard (1943), a representative of the School of Social Systems. When the concept was first proposed, it was defined as "the desire to cooperate with others". Katz and Kahn (1964) pointed out that an organization may be a very unstable system if its employees only show the behaviour required by the rules and regulations of the organization and 
there are no spontaneous, pro-organizational behaviour outside the organizational norms. Katz and Kahn (1978) stated that in an effective and continuous operation organization it is not enough to require employees to complete their own tasks on time according to certain work requirements but also to make contributions to the organization spontaneously and actively and show innovative and spontaneous behaviour, such as making constructive suggestions, constantly self-learning and experiencing.

Bateman and Organ (1983), based on Katz and Kahn (1964) research results, stated that citizenship behaviour was not explicitly stated in the formal regulations, but was beneficial to the quick development of the organization. Organ (1989) defined organizational citizenship behaviour as employees' active and self-conscious behaviour. There is no explicit regulation in the rules and regulations of the organization. It didn't influence the performance appraisal of employees, but it was beneficial to the individual behaviour of the organization. That is to say, OCB is a kind of spontaneous behaviour from the bottom of employees' hearts. If employees do not have organizational citizenship behavior, the organization will not punish it. For example, in the case of an event that damages the good image of the organization, they will stand up and maintain the image of the organization on their own initiative. Although these are not part of the work of the employees, they are good for the organization. It is difficult for managers to distinguish this situation clearly and give corresponding rewards or punishments.

Recently, Podsakoff, Blume, Whiting, and Podsakoff (2012) found that organizational citizenship behaviour was positively correlated with personal performance and customer satisfaction. Nielsen, Hrivnak, and Shaw (2013) also examined the relationship between organizational citizenship behaviour and organizational performance in group company. These researchers found that there is a positive relationship between OCB and organizational performance at the group level. Moreover, Farh J. L. (1997) is the representative of the five-dimensional structure among the Chinese scholars. On the basis of in-depth study of Western scholars' theories, he proposed that organizational citizenship behavior in Chinese context is a five-dimensional structure, including identification of organizations, altruism towards colleagues, professionalism, law-abiding, maintaining interpersonal harmony, and distinction between public and private. Affection and cultural background have also been optimized and developed in organizational citizenship behaviour scale.

Regarding the relationship between organizational citizenship behavior and management assessment, Podsakoff and colleagues (2009) found that organizational citizenship behavior accounted for $42.9 \%$ of the variance in management performance evaluation. The results also presented that among the ten studies included, altruism or help in the eight studies was significantly associated with performance evaluation; the sportsmanship was significantly correlated with performance evaluation in five of the eight studies; Responsibility was significantly associated with performance assessment in all three studies; six of the eight studies included were significantly associated with performance evaluation. In short, it can be said that according to the above research, organizational citizenship behaviour has a significant effect on organizational performance.

\subsection{Organizational Justice and Organizational Performance}

Organizational justice addresses the common dilemma of understanding and describing human behavior in an organization, as well as the cognitive framework of attitudes, values, norms, and expectations shared by organizational members" (Faldetta, 2016). Javahery Kamel (2009) stated that organizational justice influenced people's perceptions on groups or job assignments in which they work. In other words, organizational justice influences collective consciousness and interpersonal perceptions. As these two values are strongly related to organizational performance, this research decided to include organizational justice construct in its conceptual framework. Three constructs are proposed under the organizational justice, they are distributive justice, procedural justice and interactional justice.

\subsubsection{Distributive Justice}

Distributive justice is an individual's perception of the justice of the rewards received, and the evaluation of the final distribution results based on certain criteria. It also known as outcome justice (Moorman, 1991; Johnson, 2007; Javahery, 2009). Depending on the Adams' equity theory (1963; 1965), distributive justice comes from the comparison of work outcomes, taking into account the input of some reference others and the concept of comparison used by employees. Most natural environments have some reasonable reference comparisons (Ronen S. 1986).

Distributive justice also refers to the justice of the results and rewards obtained by employees (Neuhoff \& Moorman, 1993). It is mainly related to cognitive, emotional and behavioural responses to specific outcomes (Moorman, 1991; Johnson, 2009). Pan Xiao Fu (2010), Yan Dan and Zhang Lijun (2010), Liao Le Le (2018) explored the relationship among the distributive justice and OCB and organizational performance from the perspective of China cultural background. The study result showed that distributive justice can influence 
organizational performance. The OCB played a mediation role. In other words, when a particular outcome is considered fair it should affect people's emotions, cognition and ultimately their behaviours. These behaviours can influence the organizational performance (Greenberg, 2004; Fox S, Spector P E, Miles D, 2001; Rashi, Mnia, \& Hassanzad, 2009). According to the above researches, the following hypotheses were put forward:

H1a: There is a significant relationship between distributive justice and employees' OCB of SMEs in China.

H1b: There is a significant relationship between distributive justice and organizational performance of SMEs in China.

\subsubsection{Procedural Justice}

Procedural justice refers to the process and procedure of event handling and decision-making, which is fair to both stakeholders and parties (Lind \& Allan, 1989). In this process, there is no unfair and unreasonable result caused by human deviation. Therefore, it is also one of the guarantees to ensure the justice of results (Johnson R E, 2006). Specifically speaking, procedural justice is to ensure and achieve justice and it is a system design for event handling process. Procedural justice requires that the designer of a procedure dealing with an event, after considering and synthesizing various factors affecting the process, formulate a set of system and legal system to ensure transparency and justice, so as to realize the protection of interests and legitimate and reasonable rights of the parties and stakeholders in the same procedure (Greenberg, 1986).

Moorman (1991), Farh (1997) analysed the relationship between procedural justice and OCB. The result indicated that procedural justice had positive correlation with OCB, which leaded to positive effect on organizational performance. This is because the implementation of procedural justice in an organization would motivate employee to have a great emotion and behaviour to improve organizational performance (Kim \& Maurborgne, 1996). According to the above researches, the following hypotheses were proposed:

H2a: There is a significant relationship between procedural justice and employees' OCB of SMEs in China.

$\mathrm{H} 2 \mathrm{~b}$ : There is a significant relationship between procedural justice and organizational performance of SMEs in China.

\subsubsection{Interactional Justice}

Interactional justice focuses on the impacts of the process executor's attitude and manner towards employees on employees' perception of fairness in the process of implementation(Dan S C, Audrey S.,2008) Interpersonal justice reflects the degree of politeness and respect for employees by those in power who execute procedures and determine outcomes; Bies R J (1987) and Burton J P (2011) stated that interactional justice is the most common one in the organizations compared to distributive justice and procedural justice because employees experience it every day. They uncovered that only a very small part of the unfair events people experiences every day can be attributed to the distributive justice and procedural justice.

Moorman (1991) also found that interactional justice positively affected employees' organizational citizenship behaviour. Karriker (2007) and Rego and Chanha (2010) found that organizational citizenship behaviour was significantly affected by interactional justice and in turn employees' citizenship behaviour had a positive effect on the organizational performance. This is because interactional justice involves the source of justice and all aspects of the communication process between the recipients, such as courtesy, honesty, respect and transfer information. Thus, when organizational employees feel the interactional justice, they incline to improve organizational performance. This leads to the following hypotheses:

H3a: There is a significant relationship between interactional justice and employees' OCB of SMEs in China.

$\mathrm{H} 3 \mathrm{~b}$ : There is a significant relationship between interactional justice and organizational performance of SMEs in China.

\subsubsection{Mediating Role of Organizational Citizenship Behavior}

Organ (1993) proposed that the accumulation of organizational citizenship behaviour can improve organizational performance. In particular, OCB helps to create a positive team atmosphere, create a more enjoyable work environment, and enhance the organization's ability to adapt to environmental changes and create organizational social capital, thereby improving the efficiency of employees and organizational performance. Over the years, there have been many such studies, but they are most based on theoretical basis inference, and empirical research is still very few. Therefore, in this study, OCB was assumed to have a potential to mediate the relationships between antecedents (distributive justice, procedural justice, interactional justice) and organizational performance. This argument leads to the following hypotheses: 
H1c: The relationship between distributive justice and organizational performance is mediated by organizational citizenship behaviour

$\mathrm{H} 2 \mathrm{c}$ : The relationship between procedural justice and organizational performance is mediated by organizational citizenship behaviour

H3c: The relationship between interactional justice and organizational performance is mediated by organizational citizenship behaviour

\section{Research Methodology}

This study adopted disproportionate stratified random sampling to collect data from the SMEs' employees in of China. The stratified random sampling is a method of sampling that is referred to the standard of the population group that is called strata. The strata of this research were type of industries in China. According to Gay and Airasian (2000), random sampling is a method in which all individuals have equal and independent opportunities to be selected as subjects in the selected population. The ease of use factor represents the biggest advantage of random sampling. In short, disproportionate stratified random sampling was used to collect data from different industries in China. The study takes samples from as many regions, industries and types of employees spanning in SMEs of China by sending email questionnaire. As stated above, the total of 400 employees in SMEs of China were randomly selected. The data collection period took approximately four months from October 2018 to January 2019. The questionnaire of study used a Likert seven-point scale from 1 (strongly disagree) to 7 (strongly agree).

\subsection{Organizational Justice Scale}

Organizational justice scale was adopted from Neuhoff and Moorman (1993). The scale was consisted of 12 items. It includes three parts to measure distributive justice, procedural justice, interactional justice. Every part has four items. As show in Table 1.

Table 1. Items constituting organizational justice

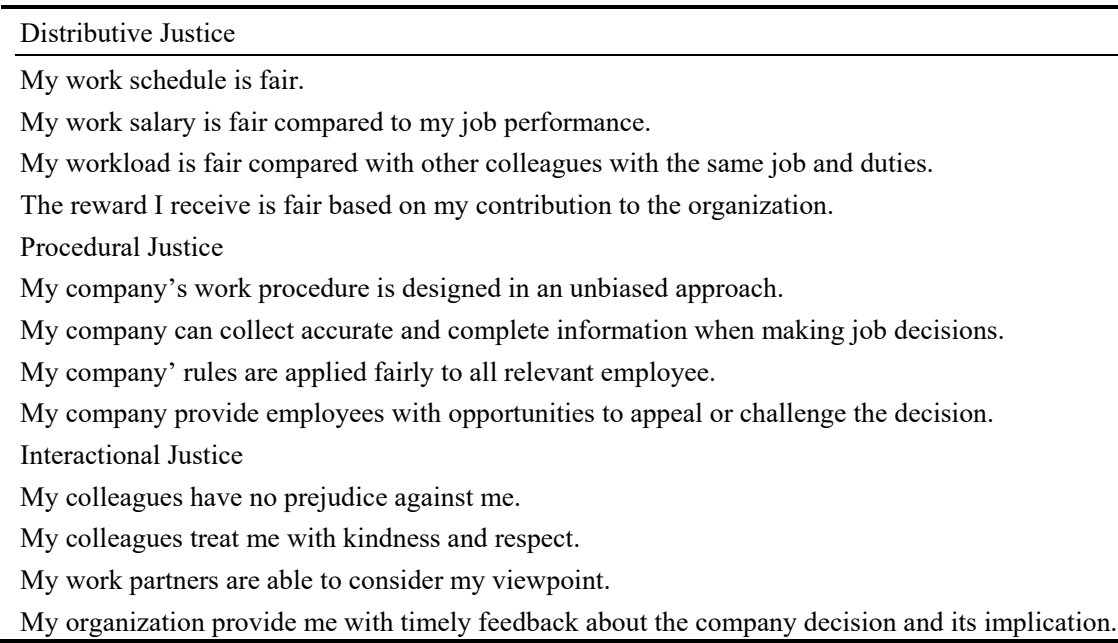

\subsection{Organizational Citizenship Behaviour Scale}

Organizational citizenship behaviour was examined using the scale developed by Farh J. L. (1997), Organizational citizenship behavior is the mediating variable which refers to employees' actions and activities that benefit the organization but have not been explicitly or directly confirmed in the formal compensation system of the organization. Twenty items were adopted to the measure this variable. As shown in the Table 2. 
Table 2. Items constituting organizational citizenship behavior

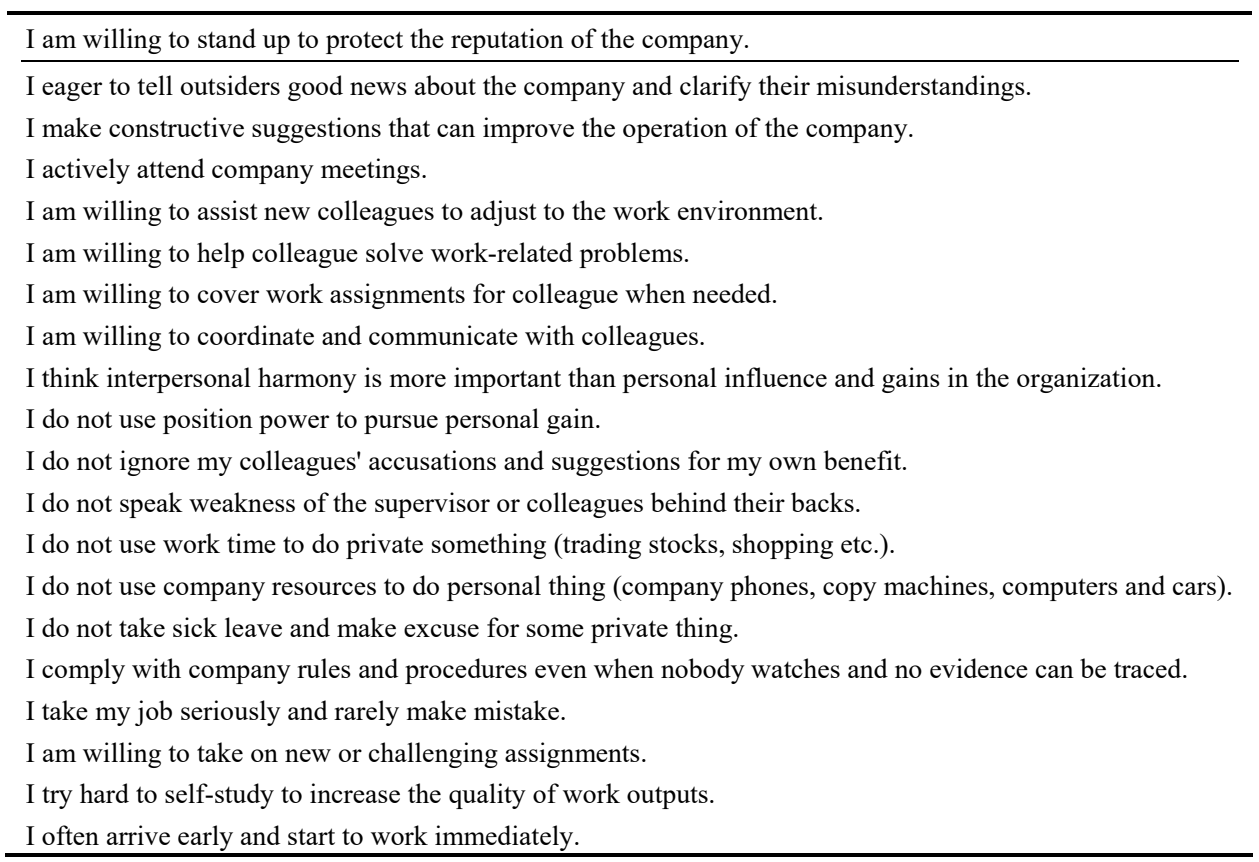

\subsection{Organizational Performance Scale}

Organizational performance scale was adopted from Wang, F. J. (2010). Organizational performance is the dependent variable and was defined as the achievement of organizational goals. Seven items were adopted to the measure this variable. As shown in Table 3.

Table 3. Items constituting organizational performance

My organization has made good use of knowledge and skills in looking for ways to become more efficient.

My company's employee productivity has improved.

The quality of work performed by my current coworkers in work group is high.

The occurrence of goal attainment is very high in my organization.

The company's after-tax net income growth rate has been increased.

The company's image is better than that of the competitors.

The customer satisfaction toward my organization is very high.

\section{Research Findings}

Out of 400 questionnaires were distributed, 251 were returned. This leaded to a $62.7 \%$ response rate. Depending on the Sekaran (2003), 30\% response rate is thought sufficient to have a survey research. According to the theory, the response rate $(62.7 \%)$ of this study was higher than the recommendation rate. In return, the results of this study can be extended to the population.

\subsection{Profile of the Respondents}

The demographic background of the respondents was showed in Table 4. Out of 251 respondents, $55.4 \%$ of them were female and $44.6 \%$ were male. The respondents were age below 25 years old (24.3\%), 26 to 36 years old (33.1\%), 36 to 45 years old $(15.1 \%)$ and more than 45 years old $(27.5 \%)$. The respondents $(56.6 \%)$ had at least were the bachelor degree holders. Table 4 also shows that the respondents were from various industries including industry $(6.0 \%)$, trade $(3.2 \%)$, education $(38.6 \%)$, health care $(13.5 \%)$, hotel and restaurant $(6.0 \%)$, agriculture $(2.4 \%)$ and others $(20.3 \%)$. 
Table 4. Demographic profile of the respondents $(\mathrm{N}=251)$

\begin{tabular}{lll}
\hline & Frequency & Percentage \\
\hline Gender & 112 & 44.6 \\
Male & 139 & 55.4 \\
Female & & \\
Age & 61 & 24.3 \\
25years and below & 83 & 33.1 \\
26 to 36 years & 38 & 15.1 \\
36 to 45 years & 69 & 27.5 \\
45 years and above & & \\
Educational Level & 16 & 6.4 \\
High school and below & 55 & 21.9 \\
College & 142 & 56.6 \\
Bachelor & 38 & 15.1 \\
Master and above & & \\
Type of Industry & 15 & 6.0 \\
Industry & 8 & 3.2 \\
Trade & 122 & 48.6 \\
Education & 34 & 13.5 \\
Healthcare & 15 & 6.0 \\
Hotel and restaurant & 6 & 2.4 \\
Agriculture & 51 & 20.3 \\
Others & & \\
\hline
\end{tabular}

\subsection{Reliability Analysis}

According to Sekaran's (2003) suggestion, for testing the reliability of the research instrument, this study adopted the internal consistency method, which was measured by Cronbach's alpha. Based on the recommendations of Nunnall and Berntein (1994) and Nunnally (1978), the Cronbach coefficient alpha values greater than 0.65 for measuring the reliability are reliable. Table 5 provides the Cronbach coefficient alpha values of independent variables are greater than 0.70 , ranging from 0.792 to 0.913 , exceeding the acceptable value recommended. Thus, the instrument was reliable.

Table 5. Reliability coefficients for variables

\begin{tabular}{|c|c|c|c|c|}
\hline Variable & $\begin{array}{l}\mathrm{N} \text { of Original } \\
\text { Item }\end{array}$ & $\begin{array}{l}\mathrm{N} \text { of Deleted } \\
\text { Item }\end{array}$ & $\begin{array}{l}\mathrm{N} \text { of New } \\
\text { Items }\end{array}$ & Cronbach Alpha \\
\hline Performance & 7 & - & 7 & 0.913 \\
\hline Organizational Citizenship Behavior & 20 & - & 20 & 0.961 \\
\hline \multicolumn{5}{|l|}{ Organizational Justice } \\
\hline Distributive Justice & 4 & - & 4 & 0.871 \\
\hline Procedural Justice & 4 & - & 4 & 0.846 \\
\hline Interactional Justice & 4 & - & 4 & 0.792 \\
\hline
\end{tabular}

\subsection{Correlation Analysis}

As indicated in Table 6, organizational justice showed significant association with organizational performance ( $\mathrm{r}$ $=0.480, \mathrm{p}<0.01)$. Organizational justice also has a significant connection with $\mathrm{OCB}(\mathrm{r}=0.569, \mathrm{p}<0.01)$. Interactional justice showed the highest association to organizational performance $(\mathrm{r}=0.451, \mathrm{p}<0.01)$ and $\mathrm{OCB}$ $(\mathrm{r}=0.592, \mathrm{p}<0.01)$, followed by procedural justice and distributive justice. 
Table 6. Relationship among organizational justice, OCB and organizational performance

\begin{tabular}{|c|c|c|c|c|c|c|c|}
\hline & & Performance & $\mathrm{OCB}$ & OJ & DJ & $\mathrm{PJ}$ & $\mathrm{IJ}$ \\
\hline Performance & & 1 & & & & & \\
\hline Organizational & Citizenship & $.731^{* *}$ & 1 & & & & \\
\hline Organizational Justice & & $.480^{* *}$ & $.569^{* *}$ & 1 & & & \\
\hline Distributive Justice & & $.394^{* *}$ & $.455^{* *}$ & $.898^{* *}$ & 1 & & \\
\hline Interactional Justice & & $.451^{* *}$ & $.592^{* *}$ & $.840^{* *}$ & $.647^{* *}$ & $.623^{* *}$ & 1 \\
\hline
\end{tabular}

\subsection{Multiple Regression Analysis}

\subsubsection{Effect of Predictors on Organizational Performance}

Table 7 provides the finding of regression analysis, which examined the effect of all predictors on organizational performance. Results showed that all predictors explained 49.7 percent of variance in organizational performance $\left(\mathrm{R}^{2}=0.497, \mathrm{~F}=18.023, \mathrm{p}<0.01\right)$. Two predictors had significant relationship with organizational performance. The predictors were distributive justice $(p=0.043, p<0.05)$, interactional justice $(p=0.049, p<0.05)$.

Table 7. Effect of predictors on organizational performance

\begin{tabular}{llll}
\hline & $\mathrm{B}$ & $\mathrm{T}$ & Sig. \\
\hline Distributive Justice & -.112 & -2.039 & .043 \\
Procedural Justice & -.011 & -.179 & .858 \\
Interactional Justice & -.147 & -1.975 & .049 \\
$\mathrm{R}^{2}$ & 0.497 & & \\
$\mathrm{~F}$ & 18.023 & & \\
Sig. & 0.000 & & \\
\hline
\end{tabular}

\subsubsection{Effect of Predictors on Organizational Citizenship Behavior}

Next table, Table 8 illustrates the finding of regression analysis to examine the direct effect of predictors on OCB. Overall, the studied predictors explained $75.1 \%$ of $\mathrm{OCB}\left(\mathrm{R}^{2}=0.751, \mathrm{~F}=55.082, \mathrm{p}<0.01\right)$. Three predictors showed significant effect on OCB. The predictors were distributive justice $(p=0.09, p<0.05)$, procedural justice $(\mathrm{p}=0.048, \mathrm{p}<0.01)$, interactional justice $(\mathrm{p}=0.006, \mathrm{p}<0.05)$,

Table 8. Effect of predictors on organizational citizenship behavior

\begin{tabular}{llll}
\hline & B & T & Sig. \\
\hline Distributive Justice & -.096 & -2.618 & .009 \\
Procedural Justice & -.084 & -.1989 & .048 \\
Interactional Justice & .137 & 2.770 & .006 \\
$\mathrm{R}^{2}$ & 0.751 & & \\
$\mathrm{~F}$ & 55.082 & & \\
Sig. & 0.000 & & \\
\hline
\end{tabular}

\subsubsection{Effect of Organizational Citizenship Behavior on Organizational Performance}

Lastly, this section also examined the effect of OCB on organizational performance. Result of regression analysis is illustrated in Table 9. Table 9 indicates that organizational citizenship behavior explained 39.3 percent variance of organizational performance $\left(\mathrm{R}^{2}=0.393, \mathrm{~F}=161.524, \mathrm{p}<0.01\right)$. The coefficient of $\mathrm{OCB}$ on organizational performance was significant $(B=0.661, t=12.709, p<0.01)$, indicating the significant effect of OCB on organizational performance. 
Table 9. Effect of organizational citizenship behavior on organizational performance

\begin{tabular}{llll}
\hline & B & T & Sig. \\
\hline Organizational Citizenship Behavior & 0.661 & 12.709 & 0.000 \\
$\mathrm{R}^{2}$ & 0.393 & & \\
$\mathrm{~F}$ & 161.524 & & \\
Sig. & 0.000 & & \\
\hline
\end{tabular}

4.4.4 Mediating Effect of Organizational Citizenship Behavior on the Relationships between Predictors and Organizational Performance

Result of regression analysis to examine the mediating effect of organizational citizenship behavior is illustrated in Table 10. Out of three predictors tested, only three of them has fulfilled path ' $a$ ' and only one had fulfil path ' $c$ '. The model also meets the requirement in path ' $b$ ' when OCB significantly contribute to organizational performance. Based on the requirement outlined by Baron and Kenny (1986), OCB only mediates the relationships between procedural justice and organizational performance. OCB failed to mediate the relationships between other two variables and organizational performance.

Table 10. Mediating Effect of Organizational Citizenship Behavior on the Relationships between Predictors and Organizational Performance

\begin{tabular}{|c|c|c|c|}
\hline & $\mathrm{B}$ & $\mathrm{T}$ & Sig. \\
\hline \multicolumn{4}{|l|}{ Equation a (IV to MV) } \\
\hline Distributive Justice & -.112 & -2.618 & .009 \\
\hline Procedural Justice & -.097 & -.1989 & .048 \\
\hline Interactional Justice & .132 & 2.770 & .006 \\
\hline \multicolumn{4}{|c|}{ Equation $\mathrm{b}$ (MV to DV) } \\
\hline $\mathrm{OCB}$ & 0.627 & 12.079 & 0.000 \\
\hline \multicolumn{4}{|l|}{ Equation c (IV to DV) } \\
\hline Distributive Justice & -.124 & -2.039 & .043 \\
\hline Procedural Justice & -.012 & -.179 & .858 \\
\hline Interactional Justice & -.134 & -1.975 & .049 \\
\hline \multicolumn{4}{|c|}{ Equation c' (X \& M - Y) } \\
\hline Distributive Justice & .025 & .491 & .624 \\
\hline Procedural Justice & .119 & 2.242 & .026 \\
\hline Interactional Justice & -.047 & -.805 & .422 \\
\hline
\end{tabular}

According to Table 10, the following results were obtained. As illustrated in Figure 2, the effect of procedural justice on organizational performance with significant level $\mathrm{p}<0.01$ to not significant $(\mathrm{p}>0.05)$. This result indicated that $\mathrm{OCB}$ has partially mediates the relationship between procedural justice and organizational performance.

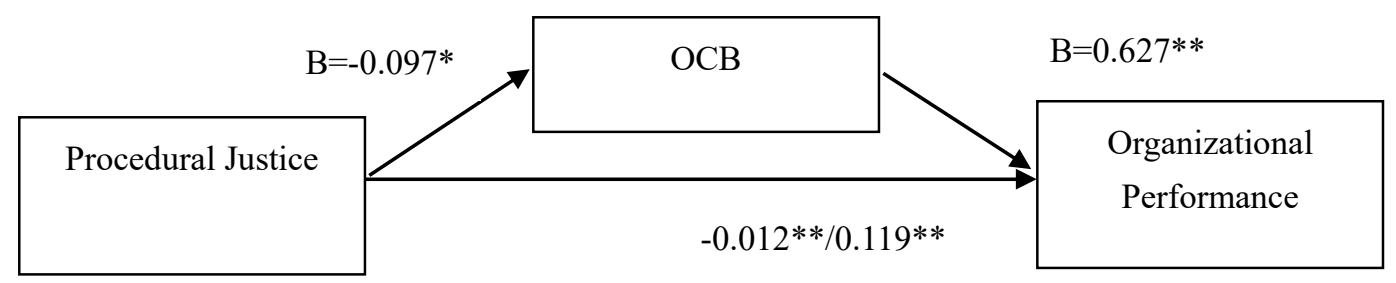

Figure 2. Mediating effect of OCB on the relationship between procedural justice and organizational performance 


\section{Discussion}

This study uses a structural model and data analysis to explore the direct and indirect effects of organizational justice on organizational performance. This research can timely to assist SMEs in improving their performance through a synergy created from organizational citizenship behavior among employees. And the finding of study can also add to more knowledge about the relationships among the research variables.

Through the correlation analysis and regression analysis from the study, it can be observed that there were significant correlations between distributive justice, procedural justice, interactive justice and organizational performance of SMEs in China. The interactional justice gained the highest correlation coefficients and followed by procedural justice and distributive justice. Through regression analysis, H1b, H3b were supported.H2b was rejected. It can be observed that distributive justice and interactive justice were positively and significantly influenced organizational performance but procedural justice was not positively and significantly influenced organizational performance. Thus, according to the finding of the study, we can know when employees think that their input has been rewarded properly can they feel organizational fairness, and then they will work hard to improve personal work performance, thereby improving organizational performance. If employees can not feel organizational justice, it will reduce work efficiency and even lead to negative idleness. Only by realizing organizational justice, can employees' work performance be positively affected. Therefore, organizational justice is an important factor to measure the ability of enterprise management, and also an important part of the core competitiveness of enterprises. It has a very important impact on employees' work cognition and practice.

Through the correlation analysis and regression analysis, it can also be seen that there were significant correlations between distributive justice, procedural justice, interactive justice and organizational citizenship behavior of employees in SMEs in China. This can show that the higher the perception of organizational justice of employees in SMEs, the better the perception on organizational citizenship behavior. Interactional justice obtained the highest coefficient and followed by procedural justice and distributive justice. Through regression analysis, H1a, H2a, H3a were supported, it was uncovered that distributive justice, procedural justice and interactive justice were positively and significantly influenced organizational citizenship behavior. Thus, it could be said that the results of this study were parallel with previous studies and supported the axiom that organizational justice are important in the organization. When employees feel fair treatment in organization, they will do more civic behavior in favor of the organization and bring more benefits to the organization.

This study found that $\mathrm{H} 2 \mathrm{c}$ was supported in the practical setting whereas other hypotheses $\mathrm{H} 1 \mathrm{c}, \mathrm{H} 3 \mathrm{c}$ were rejected. In other words, the relationships between procedural justice and organizational performance were mediated by the organizational citizenship behavior. On the other hand, the relationships between distributive justice, interactional justice and organizational performance were not mediated by the organizational citizenship behavior. And the study also found that the organizational citizenship behavior has a significant effect on the organizational performance. Therefore, though the finding of the study, we can know that organizational citizenship behavior can has a mediating role between procedural justice and organizational performance, this is a supplement to previous research. Therefore, implicit in this is that employees must be equipped with relevant intrinsic values and inner fair needs so that they have high level of citizenship behavior towards the company and in turn willing to contribute towards achieving SMEs' performance goals actively.

To sum up, through the result of study, SMEs should further improve the salary and welfare system, adhere to the "people-oriented" principle, the salary level of staff should be basically consistent with that of other similar organizations, and the salary of their own units should be determined according to the actual development of the local economy. It is suggested to establish a fair and multi-channel promotion mechanism; material returns from promotion and personal social status. This improvement can motivate them to generate organizational citizenship behavior. Executive Service Center staff can be assessed based on task performance and peripheral performance. Task performance is directly related to the content of job responsibilities. Peripheral performance is organizational citizenship behavior. It is a spontaneous initiative beyond post responsibilities. The official assessment and social assessment should be combined, pay attention to usual assessment, be good at collecting performance-related information, and have a holistic grasp of staff performance through core event method, investigation and research method, interview method, especially the surrounding performance such as organizational citizenship behavior, so as to promote the improvement of enterprise organizational performance.

Nevertheless, the limitations of this study mitigate the findings and their impact. In the aspect of variable data, the method of subjective evaluation was used to answer the survey questions. Although it has many advantages and conveniences, after all, people's subjective views will be affected by personal knowledge level, ideas and other factors. On the other hand, because of the restriction of subjective and objective conditions, the object of 
this research was SMEs of China. Although it has a strong pertinence, it also means that it restricted the popularization and application of research conclusions. And cultural differences affect employees' attitudes and behaviors. Many Chinese employees may be more sensitive to interactional justice, and more pay attention to emotional identity. Therefore, future research needs to use multinational samples to test the model.

\section{Conclusion}

The model established in this paper provides an important theoretical basis for studying organizational justice and organizational performance. First, the research results show that distributive justice and interactional justice have directly significant effect on the organizational performance, but procedural justice has an indirectly influence on the organizational performance by the mediation of organizational citizenship behavior Secondly, among the three dimensions of organizational justice, interactive justice is the best predictor of organizational performance. Thirdly, this paper further develops the theory of the relationship between organizational justice and organizational performance by exploring the influence mechanism of organizational justice on organizational performance. Thus, this study can provide more effective theoretical guidance for the development of the organization and a new conceptual framework that contains values that could develop employees' organizational citizenship behavior and in turn motivation to contribute towards achieving organizational goals actively in the workplace. The conceptual framework enables enterprise managers to deeply understand the structural model of organizational equity and organizational performance, and clarify the mechanism of the relevant elements of organizational equity for organizational performance so that they can formulate corresponding solutions to achieve more efficient and lasting. Employee incentives can effectively improve organizational efficiency and achieve the common development of organizational performance and employee performance. Moreover, this paper focused on the relationship between organizational justice and employee performance, investigates and understands the actual situation of SMEs in China. In this respect, the analyses on the main problems and shortcomings, and then the formulation of the effective improvement and improvement measures to ensure the stability, sustainability and effective development of enterprises are towards that.

\section{Acknowledgments}

During the thesis of writing, two authors contributed equally to this paper. We devoted the same time and energy to solve the difficulties encountered in the paper. Therefore, this period of time, we full of motivation to move forward and focus on my research. Here, we would like to express our highest respect and sincere thanks to our collaborator.

\section{References}

Abdin, M. J. (2017). SMEs and Our Development Goals. Social Science Electronic Publishing, 2(2), 34-56.

Admas, J. S. (1965). In equity in social exehange. In advanees in experimental social Psychology. New York: Academie Press.

Aharon, T., Gil, S. (2014). Organizational citizenship behavior, organizational justice, job stress, and work family conflict: Examination of their interrelationships with respondents from a non-Western culture. Review of psychological organization,(05), 35-42. https://doi.org/10.5093/tr2014a5

Alexander, S., \& Ruderman, M. (1987). The role of procedural and distributive justice in organizational behavior[J]. Social Justice Research, 1(2), 177-198. https://doi.org/10.2139/ssrn.2923886

Ambrose, M. L., \& Schminke, M. (2003). Organization structure as a moderator of the relationship between procedural justice, interactional justice, perceived organizational support, and supervisory trust. Journal of Applied Psychology, 88(2), 295-305. https://doi.org/10.1037/0021-9010.88.2.295

Ambrose, M. L., \& Schminke, M. (2009). The role of overall justice judgments in organizational justice research: A test of mediation.[J]. Journal of Applied Psychology, 94(2), 491-500. https://doi.org/10.1037/a0013203

Bateman, T. S., \& Organ, D. W. (1983). Job Satisfaction and the Good Soldier: The Relationship between Affect and Employee "Citizenship". Academy of Management Journal, 26(4):587-595. https://doi.org/10.2307/255908

Bies, R. J., \& Moag, J. S. (1986). Interactional justice: Communication criteria of fairness. Research on negotiation in organizations.

Burton, J. P., \& Jenny, M. H. (2011). Aggressive reactions to abusive supervision: The role of interactional justice and narcissism. Scandinavian Journal of Psychology, 52(4), 389-398. https://doi.org/10.1111/j.1467-9450.2011.00886.x 
Cai, N., Chen, G. D. (2001). On the Growth and Measurement of Small and Medium-sized Enterprises. Social Science Front, (01), 15-18.

Chen, G. Q., \& Liu, W. (2017).The effects of internal learning, external learning and their synergies on organizational performance: A study on the moderating effects of internal structure and external environment. China Management Science, (5), 43-56.

Cheung, M. F. Y., \& Law, M. C. C. (2013) Relationships of Organizational Justice and Organizational Identification: The Mediating Effects of Perceived Organizational Support in Hong Kong. Asia Pacific Business Review, 14(2), 13-231.

Cole, M. S., Bernerth, J. B., Walter, F., \& Holt, D. T. (2010). Organizational justice and individuals' withdrawal: unlocking the influence of emotional exhaustion. Journal of Management Studies, 47(3), 367-390. https://doi.org/10.1111/j.1467-6486.2009.00864.x

Colquitt, J A. (2001). On the dimensionality of organizational justice: A construct validation of a measure. Journal of Applied Psychology, 86, 386-400.

Colquitt, J. A., Conlon, D. E., Wesson, M. J., Porter, C., \& Ng, K. Y. (2001). Justice at them illennium: A meta-analytic review of 25 years of organizational justice research. Journal of Applied Psychology, 86, 425-445. https://doi.org/10.1037//0021-9010.86.3.425

Cropanzano, R., \& Ambrose, M. L. (2001).Procedural and distributive justice are more similar than you think:A monistic perspective and a research agenda. In J. Greenberg, \& R Cropanzano (Eds.), Advances in organizational justice. Lexington. MA:New Lexington Press.

Cropanzano, R., \& Greenberg, J. (1997). Progress in Organizational Justice: Tunneling Through the Maze. Review of Industrial and Organizational Psychology, 317-372.

Cui, J. (2017). The relationship between organizational justice, self-efficacy and organizational citizenship behavior. Shandong University.

Dailey, R. C., Kirk, D. J. (1992). Distributive and procedural justice as antecedents of jobs satisfaction and intent to turnover. Academy of Management Journal, (45), 305-317. https://doi.org/10.1177/001872679204500306

Dan, S. C., \& Audrey, S. L. (2008). Manager Trustworthiness or Interactional Justice? Predicting Organizational Citizenship Behaviors. Journal of Business Ethics, 83(3), 453-467. https://doi.org/10.1007/s10551-007-9631-x

Dawes, J. (2008). Do data characteristics change according to the number of scale points used? An experiment using 5-point, 7-point and 10-point scales. International Journal of Market Research, 50(1), 61-77. https://doi.org/10.1177/147078530805000106

Delaney, J. T., \& Huselid, M. A. (1996). The Impact of Human Resource Management Practices on Perceptions of Organizational Performance. Academy of Management Journal, 39(4), 949-969. https://doi.org/10.2307/256718

Delaney, J. T., \& Huselid, M. A. (1996).The Impact of Human Resource Management Practices...Nonprofit Organizations. Academy of Management Journal, (02), 949-969.

Faldetta, G. (2016). Organizational caring and organizational justice: Some implications for the employment relationship. International Journal of Organizational Analysis, 8(1), 34-57.

Farh, J. L., \& Podsakoff, P. M. (1990). Organ D W. Accounting for Organizational Citizenship Behavior: Leader Fairness and Task Scope versus Satisfaction. Social Science Electronic Publishing, 16(4), 705-721. https://doi.org/10.1177/014920639001600404

Fox, S., Spector, P. E., \& Miles, D. (2001). Counterproductive work behavior (CWB) in response to job stressors and organizational justice: Some mediator and moderator tests for autonomy and emotions. Journal of Vocational Behavior, 9(3), 291-309. https://doi.org/10.1006/jvbe.2001.1803

Gay, L. R., \& Airasian, P. (2000). Educational research: Competencies for analysis and application (6th ed.). Upper Saddle River, NJ: Prentice-Hall.

Greenberg J. (1986). The Distributive Justice of Organizational Performance Evaluations. Justice in Social Relations. 
Hassanreza, Z., \& Keyvan, S. (2011). Role of procedural justice, trust, job satisfaction, and organizational commitment in Organizational Citizenship Behavior of teachers: Proposing a modified social exchange model. Procedia-Social and Behavioral Sciences, (11), 1472-1481. https://doi.org/10.1016/j.sbspro.2011.11.387

Hauenstein, N. M. T., McGonigle, T., \& Flinder, S. W. (2001). A meta-analysis of the relationship between procedural justice and distributive justice: implications for justice research. Employee Responsibility and Rights Journal, 13(1), 39-56.

Hillman, A. J, \& Keim, G. D. (2001). Shareholder Value, Stakeholder Management, and Social Issues: What's The Bottom Line? Strategic Management Journal, 22(2), 125-139. https://doi.org/10.1002/1097-0266(200101)22:2\%3C125::aid-smj150\%3E3.0.co;2-h

Hong, Z. S. (1998). Research on the Impact of Organizational Justice on Organizational Citizenship Behavior Perspective of Trust Relations. National Sun Yat-sen University.

James, G. M., \& Roberts, I. S. (1997). Organizational Performance as a Dependent Variable. Organization Science, 8(6), 698-706.

Jiao, C., Richards, D. A., \& Hackett, R. D. (2013). Organizational citizenship behaviour and role breadth: a meta-analytic and cross-cultural analysis. Human Resource Management, 52(5), 697-714. https://doi.org/10.1002/hrm.21555

Jin, M. X. (2011). An Empirical Study on the Impact of Organizational Equity on Organizational Citizenship Behavior and Work Performance--Based on a Questionnaire Survey of Financial Enterprises. Shang Hai: Fu Dan University.

Johnson, R. E., Christopher, S., \& Robert, G. L. (2006). When organizational justice and the self-concept meet: Consequences for the organization and its members. Organizational Behavior \& Human Decision Processes, 99(2), 175-201. https://doi.org/10.1016/j.obhdp.2005.07.005

Johnson, S. K., Courtney, L. H., \& Miguel, A. Q. (2009). Organizational Citizenship Behavior in Performance Evaluations: Distributive Justice or Injustice? Journal of Business \& Psychology, 24(4), 409-418. https://doi.org/10.1007/s10869-009-9118-0

Kaplan, R. S., Norton, D. P. (1996). Strategic learning \& the balanced scorecard. Strategy \& Leadership, 24(5), 18-24.

Karriker, J. H., \& Williams, M. L. (2007). Organizational Justice and Organizational Citizenship Behavior: A Mediated Multifoci Model? Journal of Management Official Journal of the Southern Management Association, 35(1), 112-135. https://doi.org/10.1177/0149206307309265

Katrz D. (1964). Motivational Basis of Organizational Behavior. Behavioral Science, 9, 131-146. https://doi.org/10.1002/bs.3830090206

Kizilos, M. A., Cummings, C., \& Cummings, T. G. (2013). Howhigh-involvement work processes increase organization performance: the role of organizational citizenship behavior. [Journal of Applied Behavioural Science, 49(4), 413-436. https://doi.org/10.1177/0021886313479998

Liao, L. L. (2018). Research on the Impact of Organizational Equity on Employee Performance. Nanchang University.

Lievens, F., \& Anseel, F. (2004). Confirmatory factor analysis and invariance of an organizational citizenship behaviour measure across samples in a Dutch-speaking context. Journal of Occupational and Organizational Psychology, 77, 299-306. https://doi.org/10.1348/0963179041752727

Lin, Y. P. (2001). A Study on the Relationship between Market Orientation, Organizational Learning, Organizational Innovation and Organizational Performance -Taking Information and Electronics Industry in Science Park as an Example, unpublished doctoral dissertation, Department of Business Administration. National Sun Yat-sen University.

Lind, A. E. (1989). The Social Psychology of Procedural Justice. Critical Issues in Social Justice, 57(5), 830-838.

Liu, J. T., \& Yu, J. H. (2019). Internal Control Analysis of Small and Medium-sized Enterprises. Science and Technology Information, 17(16), 94-96. 
Long, C. S. (2013). Wan Ismail, Wan Khairuzzaman, Amin, Salmiah Mohd. The role of change agent as mediator in the relationship between HR competencies and organizational performance. International Journal of Human Resource Management, 2019-2033. https://doi.org/10.1080/09585192.2012.725080

Mcfarlin, D. B., \& Sweeney, P. D. (1992).Research Notes. Distributive and Procedural Justice as Predictors of Satisfaction with Personal and Organizational Outcomes. Academy of Management Journal, 35(3), 626-637. https://doi.org/10.5465/256489

Niehoff, B. P., \& Moorman, R. M. (1993). Justice as a mediator of the relationship between methods of monitoring and organizational citizenship behavior. Academy of Management Journal, 36(3), 327-336. https://doi.org/10.5465/256591

Nielsen, T. M., \& Hrivnak, G. A. (2009). Shaw, M. Organizational Citizenship Behavior and Performance: A Meta-Analysis of Group-Level Research. Small Group Research, 40(5), 555-577.

Organ, D. W. (1990). The motivational basis of organizational citizenship behavior. In Staw, B.M. and Cummings, L. L. (Eds), Research in Organizational Behaviour (Vol. 12, pp.43-72). Greenwich, CT: JAI Press.

Organ, D. W. (1997).Organizational Citizenship Behavior: It's Construct Clean-Up Time. Human Performance, 10(2), 85-97. https://doi.org/10.1207/s15327043hup1002_2

Organ, D. W., \& Konovsky, M. A. (1989). Cognitive versus affective determinants of organizational citizenship behavior. Journal of Applied Psychology, 74(1), 157-164. https://doi.org/10.1037//0021-9010.74.1.157

Organ, D. W., \& Moorman, R. H. (1993). Fairness and organizational citizenship behavior: What are the connections? Social Justice Research, 6(1), 5-18. https://doi.org/10.1007/bf01048730

Pan, Y. Y. (2013). Research on the Relationship between Organizational Justice and Organizational Commitment of Grass-roots Community Workers. Chong Qing University.

Paul, A. K., \& Anantharaman, R. N. (2003). Impact of people management practices on organizational performance. International Journal of Human Resource Management, 14(7), 1246-1266(21).

Peterson, R. A. (1994). A Meta-Analysis of Cronbach's Coefficient Alpha. Journal of Consumer Research, $21(2), 381$.

Podsakoff, N. P., Whiting, S. W., Podsakoff, P. M., \& Blume, B. D. (2009). Individual- and organizational-level consequences of organizational citizenship behaviours: a meta-analysis. Journal of Applied Psychology, 94(1), 122-141. https://doi.org/10.1037/e518442013-522

Podsakoff, P. M., Ahearne, M., \& MacKenzie, S. B. (1997). Organizational citizenship behaviour and the quantity and quality of work group performance. Journal of Applied Psychology, 82(2), 262-270. https://doi.org/10.1037//0021-9010.82.2.262

Podsakoff, P. M., MacKenzie, S. B., \& Podsakoff, N. P. (2012). Sources of method bias in social science research and recommendations on how to control it. Annual Review of Psychology, 63, 539-569.

Pritchard, R. D. (1995). Productivity measurement and improvement: Organizational case studies. Praeger Publishers, (7), 126.

Rego, A., Miguel, P. E C. (2010). Organisational Justice and Citizenship Behaviors: A Study in the Portuguese Cultural Context. Applied Psychology, 59(3), 404-430.

Ronen, S. (1986). Equity Perception in Multiple Comparisons: A Field Study. Human Relations, 39(4), 333-345. https://doi.org/10.1177/001872678603900403

Ruekert, R. W., Walker, O. C., Roering, K. J. (1985). The Organization of Marketing Activities: A Contingency Theory of Structure and Performance. Journal of Marketing, 49(1), 13-25. https://doi.org/10.2307/1251172

Sekaran, U. (2003). Research Method for Business: A Skill-Building Approach (4th ed.).

Smith, C. A., Organ, D. W., \& Near, J. P. (1983). Organizational citizenship behaviour: its nature and antecedents.Journal of Applied Psychology, 68(4), 653-663.

Steers, R. M. (1975). Task-goal attributes, achievement, and supervisory performance. Organizational Behavior \& Human Performance, 13(3), 392-403. https://doi.org/10.1016/0030-5073(75)90058-6 
Sutinen, R., Kivimäki, M., Elovainio, M., \& Virtanen, M. (2002). Organizational fairness and psychological distress in hospital physicians. Scandinavian Journal of Public Health, 30(3), 209-215. https://doi.org/10.1177/140349480203000307

Tang, W. X. (2019). The development status of financial management of small and medium-sized enterprises in China. Heilongjiang Science, 10(11), 124-125.

Tang, X. Y. (2015). The relationship between employees' work values, organizational commitment and organizational citizenship behavior in catering enterprises. Hunan Normal University.

Wang, F. J., Chich-Jen, S., \& Mei-Ling, T. (2010). Effect of leadership style on organizational performance as viewed from human resource management strategy. African Journal of Business Management, 4(18), 3924-3936.

Wang, S. M. (2016). Research on Policy Support for the Development of Small and Medium-sized Enterprises in China. Xiangtan University.

Wang, X. Y., Liao, J. Q., Xia, D. G., \& Chang, T. (2009). The impact of organizational justice on work performance. Industrial Engineering \& Management, 31(September), 660-677.

Xie, H. M., \& Chen, C. H. (2005). The Relationship between Market Orientation, Organizational Learning and Organizational Innovation: A Comparative Study between Mainland China and Taiwan. Science and Technology Management, (12).

Yan, D., \& Zhang, L. J. (2010). An Empirical Study on the Regulatory Role of Organizational Equity and Organizational Citizenship Behavior-Organizational Commitment. Industrial Engineering, 13(5), $106-111$.

Zhao, L. M. (2016). Dilemma and Countermeasure of Innovation and Upgrading of Small and Medium-sized Enterprises. Jilin Pioneering Network, (22), 57-59.

\section{Copyrights}

Copyright for this article is retained by the author(s), with first publication rights granted to the journal.

This is an open-access article distributed under the terms and conditions of the Creative Commons Attribution license (http://creativecommons.org/licenses/by/4.0/). 